\title{
TLR4 inhibitor attenuates amyloid- $\beta$-induced angiogenic and inflammatory factors in ARPE-19 cells: Implications for age-related macular degeneration
}

\author{
LI CHEN $^{1,2}$, YUJING BAI ${ }^{1}$, MIN ZHAO ${ }^{1}$ and YANRONG JIANG ${ }^{1}$ \\ ${ }^{1}$ Department of Ophthalmology, People's Hospital, Peking University and Key Laboratory of Vision Loss and \\ Restoration, Ministry of Education and Beijing Key Laboratory of Diagnosis and Therapy of Retinal and Choroid \\ Diseases, Beijing 100044; ${ }^{2}$ Department of Ophthalmology, Xi'an No. 4 Hospital, Xi'an, Shaanxi 710004, P.R. China
}

Received January 9, 2015; Accepted November 10, 2015

DOI: $10.3892 / \mathrm{mmr} .2016 .4890$

\begin{abstract}
Subretinally-deposited amyloid- $\beta(\mathrm{A} \beta)$ is an important factor in age-related macular degradation (AMD) often leading to irreversible blindness in the elderly population. The molecular mechanism underlying $A \beta$ deposition during AMD remains unclear. The expression of inflammatory and angiogenic factors was examined by treatment of retinal pigment epithelial (RPE) cells with the oligomeric form of $\mathrm{A} \beta$ (OA $\beta 1-42)$. Changes in the mRNA expression levels of various cytokines was detected by the QuantiGenePlex 6.0 Reagent system, and the protein expression level was determined by western blotting. Culture supernatants were detected using a multiplex cytokine assay and enzyme-linked immunosorbent assays. The in vitro tube formation was evaluated by a Matrigel assay. The present study highlights that OA $\beta 1-42$ activates the toll-like receptor 4 (TLR4), myeloid differentiation factor 88 and phosphorylation nuclear factor $-\kappa \mathrm{B}$ signaling pathway in RPE cells. Additionally, it increased the mRNA and protein expression of interleukin (IL)-6, IL-8, IL-33, vascular endothelial growth factor (VEGF), basic fibroblast growth factor (bFGF) and angiopoietin 2. Furthermore, the TLR4 inhibitor (COBRA) attenuated the expression of inflammatory and angiogenesis factors, particularly IL-6, IL-8, IL-33, bFGF and VEGF. When human umbilical vein endothelial cells (HUVECs) were co-cultured with the COBRA-treated RPE cell culture supernatant the length of the endothelial cell
\end{abstract}

Correspondence to: Professor Yanrong Jiang or Professor Yujing Bai, Department of Ophthalmology, People's Hospital, Peking University and Key Laboratory of Vision Loss and Restoration, Ministry of Education and Beijing Key Laboratory of Diagnosis and Therapy of Retinal and Choroid Diseases, 11 Xizhimen South Street, Xicheng, Beijing 100044, P.R. China

E-mail:drjyr@gmail.com

E-mail: baiyujing93@gmail.com

Key words: toll-like receptor 4 , amyloid- $\beta$, angiogenic factors, inflammatory factors, retinal pigment epithelial network (measured by calculating tip cell lengths of endothelial cells) was impaired when compared with the HUVECs that were co-cultured with the cell supernatant exposed to OA $\beta 1-42$. These results suggest that the TLR4-associated pathway may be a potential target for the treatment of AMD.

\section{Introduction}

Age-related macular degeneration (AMD) is the leading cause of blindness in the elderly population, as it results in a loss of vision due to damage to the retina. Based on clinical findings, AMD may be divided into 'dry' and 'wet' $\operatorname{AMD}(1,2)$. Drusen are often used to diagnose AMD, they are also associated with the geographic atrophy of the retinal pigment epithelial (RPE) cells in dry-AMD and increase the risk of developing the exudative form of AMD (wet-AMD) $(3,4)$. Amyloid- $\beta(A \beta)$ is an important constituent of drusen and is primarily associated with neurodegenerative processes in the brain during Alzheimer's disease (AD) $(5,6)$. Previous studies indicated that $\mathrm{A} \beta$ is also an important contributor to the progression of AMD $(3,7)$.

The $A \beta$ is a peptide that is ubiquitously and normally expressed in humans in two forms of 39- and 43-amino acids in length (termed $A \beta 40$ and $A \beta 42$, respectively) $(8,9)$. $\mathrm{A} \beta 42$ is associated with $\mathrm{AD}$ plaques that are composed of a multitude of highly aggregated $A \beta$ fibrils, and represent abnormal pathological lesions (10). A $\beta 40$, the more common and less harmful form, is present in drusen and activates the inflammatory response in RPE cells aiding in AMD progression (11). Bruban et al (12) reported that the oligomeric form of $A \beta 1-42$ (OA $\beta 1-42)$, is toxic for RPE cells in vitro and in vivo. Furthermore, subsequent studies demonstrated that $A \beta$ upregulated the inflammasome-associated factors interleukin-1 $\beta$ (IL-1 $\beta)$, IL-18 and caspase-1 $(11,13)$, and cy tokines IL-6, IL-8 and tumor necrosis factor- $\alpha$ (TNF- $\alpha)(14,15)$. Additionally, angiogenic factors have also been associated with $\mathrm{A} \beta$ in AD. Ets-1, an angiogenic transcription factor has been identified to co-localize with vascular endothelial growth factor (VEGF) and soluble $A \beta$ in the microvasculature (16). In addition, astrocytes have been shown to be involved with $\mathrm{A} \beta$-induced angiogenesis in rat hippocampal 
cells (17). Therefore, $A \beta$ may be responsible for triggering the angiogenic and inflammatory responses involved in the pathogenesis of AMD (14-18).

Toll-like receptor 4 (TLR4) is involved in microbial and autoimmune pathogenesis, as well as chronic inflammatory conditions (19). The TLR4 gene is located on the 9q32-33 chromosome region that harbors a potential AMD susceptibility locus $(20,21)$. TLR4 was also identified to be involved in the phagocytosis of the outer photoreceptor segments in RPE cells (22). Impairing phagocytosis in the photoreceptor layer, causes accumulation of lipofuscin fluorophore, which may lead to AMD. A $\beta$ may induce upregulation of TLR4 and nuclear factor $-\kappa \mathrm{B}(\mathrm{NF}-\kappa \mathrm{B})$ expression in microglia as reported by Zhou et al (23). However, the link between the TLR4 signaling pathway and A $\beta$ in RPE cells remains poorly understood.

The current study aimed to determine whether $\mathrm{A} \beta$ triggered upregulation of TLR4 and $\mathrm{NF}-\kappa \mathrm{B}$ expression and whether $A \beta$ activates the release of cytokines and growth factors via the TLR4 and $\mathrm{NF}-\kappa \mathrm{B}$ signaling pathways in RPE, thus aiding the progression of AMD. The results of the present study provide strong evidence in support of the involvement of $\mathrm{A} \beta$-induced local inflammatory response in RPE cells in the pathogenesis of AMD.

\section{Materials and methods}

RPE cell culture and cell treatment. The human ARPE19 cell line [CRL-2302; American Type Culture Collection (ATCC), Manassas, VA, USA] is a non-transformed human RPE cell line that has numerous differentiated properties typical of RPE cells in vivo. ARPE-19 cells were cultured in Dulbecco's modified Eagle's medium: F12 (Invitrogen; Thermo Fisher Scientific, Inc., Waltham, MA, USA) supplemented with $10 \%$ heat-inactivated fetal calf serum (Gibco; Thermo Fisher Scientific, Inc.). At $80 \%$ confluence, the ARPE-19 cultures were treated with $1 \mathrm{mM}$ concentrations of the $\mathrm{A} \beta$ peptides (Bachem Distribution Services GmbH, Weil am Rhein, Germany) for $30 \mathrm{~min}, 1,3,6,12$ or $24 \mathrm{~h}$ and their respective inactive reverse peptides (Bachem Distribution Services $\mathrm{GmbH}$ ), which served as controls. All of the cells were used between passage 3 and 7 . For the TLR4 inhibitor (COBRA; Novus Biologicals, LLC, San Diego, CA, USA) treatment group, cells were pre-treated with the TLR4 inhibitor, $20 \mu \mathrm{M}$ COBRA, $4 \mathrm{~h}$ prior to being exposed to the A $\beta$ peptides. COBRA interferes with interaction between TIRAP/Mal and the TIR domain of TLR 2 or TLR4.

Procedure of $A \beta$ oligomerization. A $\beta 1-42$ (H-1368), A $\beta 42-1$ (H-3976, inactive reverse control peptide of $A \beta 1-42), A \beta 1-40$ (H-1194) and $A \beta 40-1$ (H-2972, inactive reverse control peptide of $\mathrm{A} \beta 1-40)$, were used in the experiments and supplied by Bachem Holding AG (Bubendorf, Switzerland). The preparation of the oligomerization $A \beta 1-42$ has been previously described by Bruban et al (12) (technical notes on the solubilization and oligomerization of the $A \beta$ peptides supplied by Bachem Holding AG). Non-oligomerized A $\beta 1-40$ and A $\beta 1-42$ (Bachem Distribution Services $\mathrm{GmbH}$ ) were incubated at $37^{\circ} \mathrm{C}$ for 5 days and stored at $-20^{\circ} \mathrm{C}$ until they were used. Each aliquot was used only once.
Gene expression of cytokines in ARPE-19 cells using the QuantiGenePlex 6.0 Reagent system. Target-specific RNA molecules of ARPE-19 cells [TLR4: NM_003266; myeloid differentiation factor 88 (MyD88): NM_002468; NF-кB: NM_003998; IL-6:NM_000600; IL-8:NM_000584; IL-33: NM_033439; VEGF: NM_003376; basic fibroblast growth factor (bFGF): NM_002006; angiopoietin 2 (Ang2): NM_001147] were detected using the QuantiGenePlex 6.0 Reagent System according to the manufacturer's protocol (Affymetrix, Inc., Fremont, CA, USA). RNA extracted from cell lysates was captured by fluorescent microspheres (Affymetrix, Inc.). Signals of cascade amplification were detected with the Luminex 100 xMAP system and Bio-Plex software (version 5.0; Bio-Rad Laboratories, Hercules, CA, USA). The geometric means of the two housekeeping genes, peptidylprolyl isomerase B (NM_011149) and hypoxanthine phosphoribosyltransferase 1 (NM_013556) for the ARPE19 cells were used for normalizations. Fold-changes were the relative ratios between the normalized values of the four infected groups and the values of the untreated group. ARPE19 cells from three different cell samples were combined for one detection, and the experiments were repeated three times.

Multiplex cytokine assay. Procarta cytokine profiling kit (Affymetrix, Inc.) was used to simultaneously detect IL-6, IL-8, VEGF, and bFGF in the cell culture supernatants, according to manufacturer's protocol. Antibody beads $(50 \mu \mathrm{l})$ were added to each well of the filter plate and washed with wash buffer. Then, $50 \mu \mathrm{l}$ cell culture supernatant was added to each well, incubated for $1 \mathrm{~h}$ at room temperature, and washed with wash buffer. Subsequently, $25 \mu \mathrm{l}$ per well of the detection antibody was added and the filter plate was shaken at $30 \mathrm{x} \mathrm{g}$ for $30 \mathrm{~min}$ at room temperature. Following the addition of Streptavidin-phycoerythrin, the signals were detected using a Luminex 200 instrument (Bio-Rad Laboratories).

Enzyme-linked immunosorbent assay (ELISA). The levels of IL-33 and Ang2 were determined using Human IL-33 Quantikine ELISA kit (R\&D Systems, Inc., Minneapolis, MN, USA) and Human Ang2 Quantikine ELISA kit (R\&D Systems, Inc.,) according to the manufacturer's instructions. The 100- $\mu 1$ cell culture supernatant was added to the wells $\left(1 \times 10^{5}\right.$ cells/well), which was pre-coated with IL-33 and Ang2 antibodies. The absorbance was measured at $450 \mathrm{~nm}$ by microplate reader, model 450 (Bio-Rad Laboratories). All experiments were performed at least three times.

Western blot analysis. RPE cells were harvested and lysed in radioimmunoprecipitation assay buffer (1\% Nonidet P-40, $0.5 \%$ sodium deoxycholate and $0.1 \%$ sodium dodecyl sulfate in phosphate-buffered saline; Affymetrix, Inc.) and centrifuged at $25,000 \mathrm{x}$ g for $15 \mathrm{~min}$ at $4^{\circ} \mathrm{C}$. NuPAGE Bis-Tris gels (10\%; Invitrogen) were used according to the manufacturer's protocol. The membranes were blocked with $10 \%$ fat-free milk and incubated with primary antibodies overnight at $4^{\circ} \mathrm{C}$. The anti-TLR4 antibody, purchased from Abcam (ab22048; Cambridge, MA, USA) was used at a 1:1,000 dilution. The following primary antibodies were purchased from Cell Signaling Technology, Inc. (Beverly, 
A

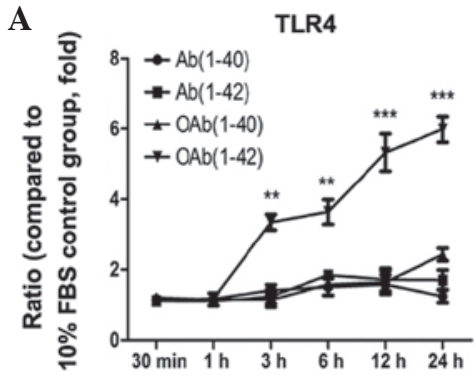

B

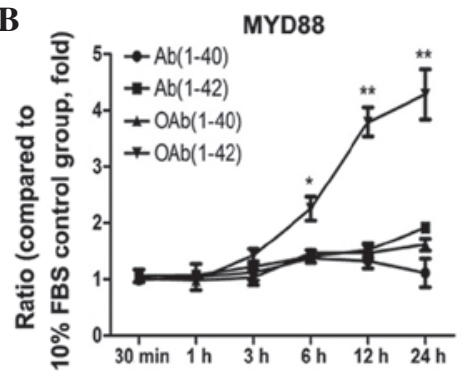

D

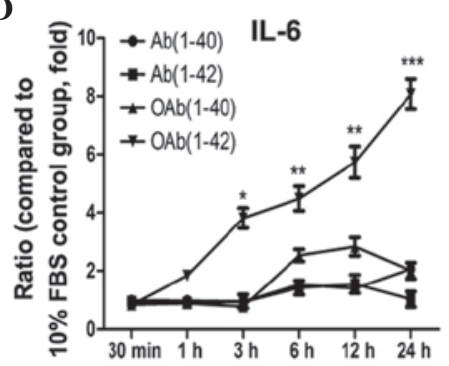

E
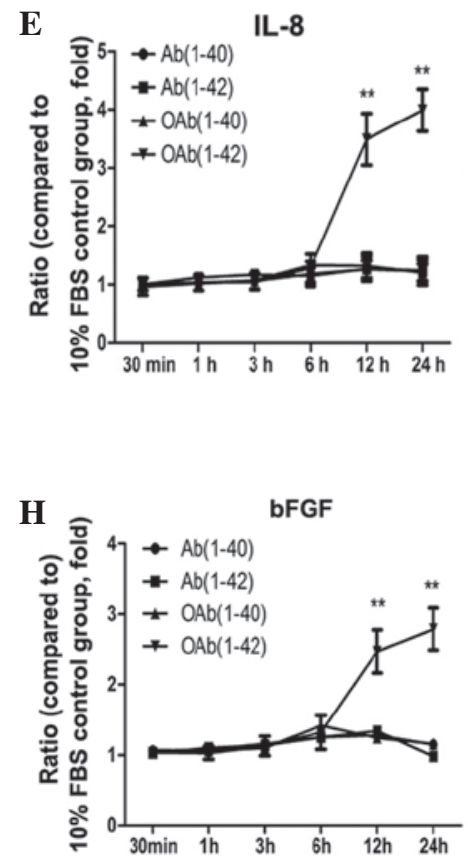

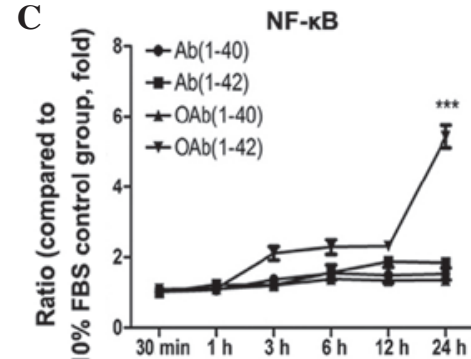

F

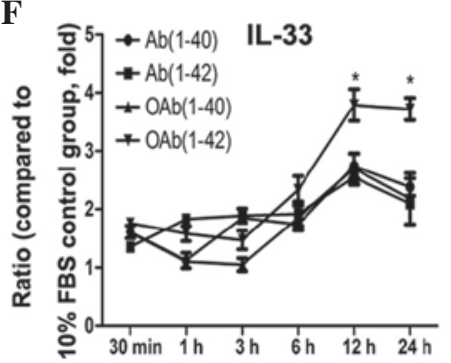

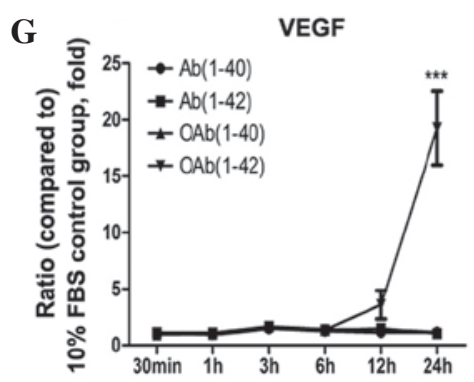

Figure 1. mRNA expression levels of cytokines in RPE cells. QuantiGene assay was used to determine the mRNA levels in RPE cells treated with or without $1 \mu \mathrm{M}$ OA$\beta 1-42$. Fold-changes were the relative ratios of (A) TLR4, (B) MyD88, (C) NF- $\kappa$ B, (D) IL-6, (E) IL-8, (F) IL-33, (G) VEGF, (H) bFGF and (I) Ang2 between the normalized values of the four infected groups and the values of the untreated group. Values are expressed as the mean \pm standard error, $\mathrm{n}=3,{ }^{*} \mathrm{P}<0.05,{ }^{* *} \mathrm{P}<0.01$ and ${ }^{* * *} \mathrm{P}<0.001$. FSB, fetal bovine serum; OA $\beta 1-42$, oligomeric form of A $\beta$; TLR4, toll-like receptor 4; MyD88, myeloid differentia-

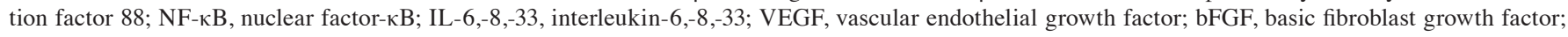
Ang2, angiopoierin-2; RPE, retinal pigment epithelial.

MA, USA) and were used at a 1:1,000 dilution: MyD88 (cat. no. 4283), phosphorylation-NF-кB (cat. no. 3033), and $\beta$-actin (cat. no. 4970). The anti-rabbit (cat. no. 7074) and anti-mouse (cat. no. 7076) horseradish peroxidase-conjugated secondary antibodies (dilution, 1:2,000 for the two; Cell Signaling Technology, Inc.) were applied for $1 \mathrm{~h}$ at room temperature. Labeled proteins were detected using an enhanced chemiluminescence western blotting system (Pierce Biotechnology, Inc., Rockford, IL, USA). Image J analysis software (version 1.49; National Institutes of Health, Bethesda, MD, USA) was used to quantify the optical density of each band. Relative changes in protein expression were calculated in relation to normal group and expressed as a fold-change. Each experiment was repeated at least three times.

Tube-formation assay. Human umbilical vein endothelial cells (HUVECs; CRL-1730, ATCC) were used in the current study for in vitro evaluation of angiogenesis as previously described (24). All RPE cells were exposed to A $\beta$; however, two treatment groups were also established, one where the cells were exposed to $20 \mu \mathrm{M}$ COBRA for $4 \mathrm{~h}$ and another where they were not. Subsequently, $200 \mu 1$ Matrigel (BD Biosciences, San Diego, CA, USA) was added to a 24 -well pre-cooled plate and then allowed to polymerize at $37^{\circ} \mathrm{C}$ for $30 \mathrm{~min}$. Trypsin-harvested HUVEC cells $\left(1 \times 10^{5}\right.$ cells/well) suspended in $300 \mu \mathrm{l}$ of the fresh assay medium were seeded onto Matrigel and incubated for $8 \mathrm{~h}$. The networks from five randomly selected fields were photographed (Eclipse 50i; Nikon Corporation, Tokyo, Japan). The length of the capillary-like structures, in two-dimensional microscope images, was measured using Image $\mathbf{J}$ software (version 1.49). The experiments were repeated three times.

Statistical analysis. Data analysis was performed using the following statistical software programs: Prism version 5.0 (GraphPad Software, Inc., San Diego, CA, USA) and SPSS version 16.0 (SPSS, Inc., Chicago, IL, USA). All data are presented as the mean \pm standard error. Data sets were examined by one-way analysis of variance followed by a post hoc 

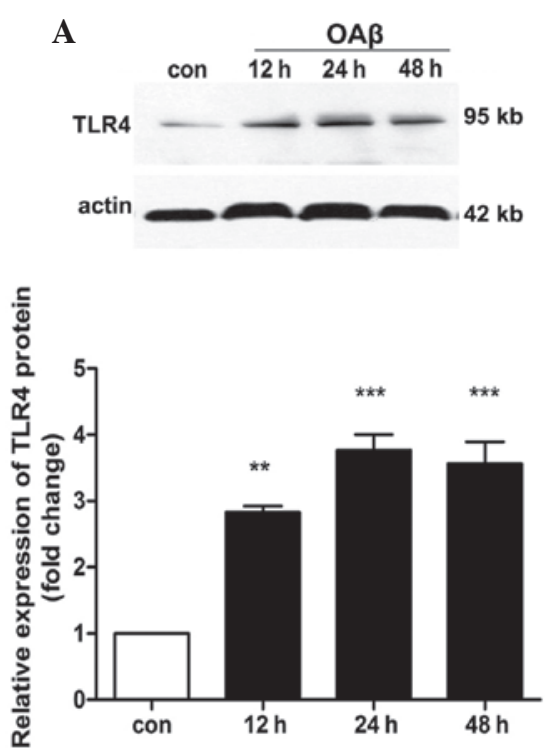
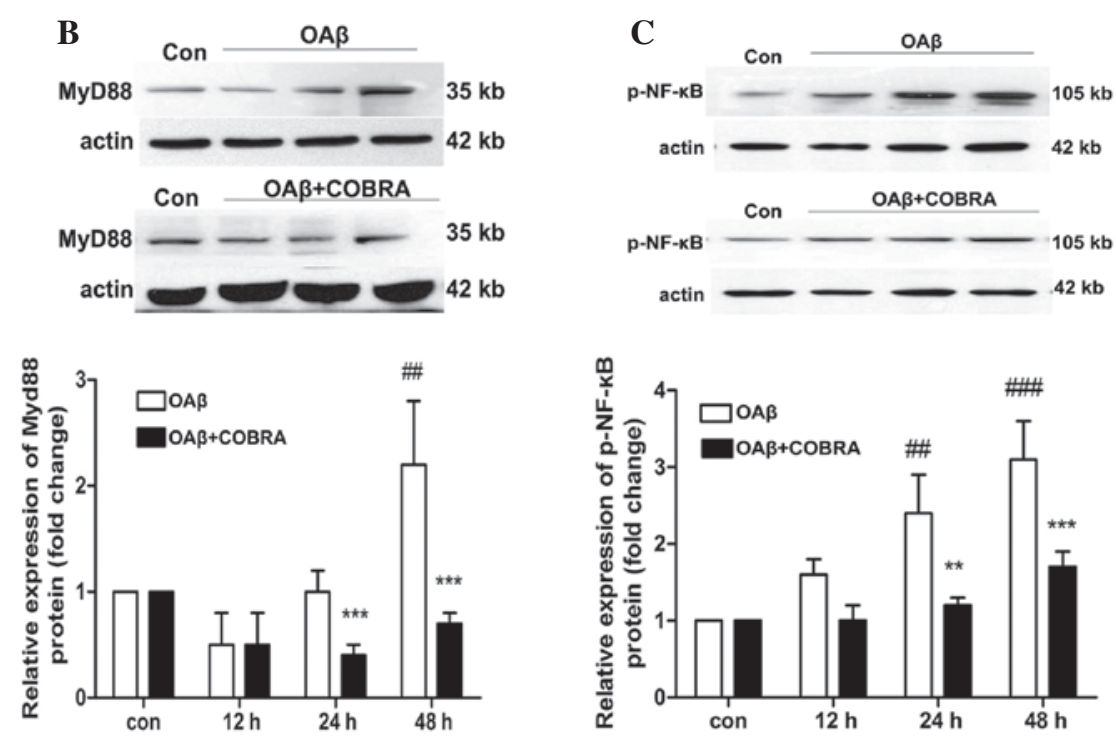

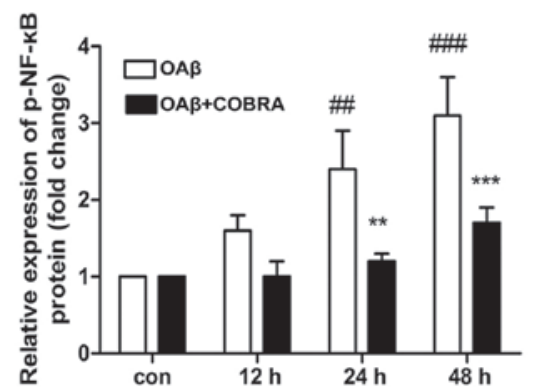

Figure 2. (A) Protein expression and western blotting of TLR4 in RPE cells. Effects of COBRA on the protein expression of (B) MyD88 and (C) p-NF- $\kappa \mathrm{B}$ in RPE cells induced by OA $\beta 1-42$. Three independent experiments were performed and data are expressed as the mean \pm standard error. ${ }^{* *} \mathrm{P}<0.01$ and ${ }^{* * *} \mathrm{P}<0.001$ vs. control group; ${ }^{\# \#} \mathrm{P}<0.01$ and ${ }^{\# \# \#} \mathrm{P}<0.001$ vs. OA $\beta$ + COBRA group. OA $\beta 1-42$, oligomeric form of A $\beta$; TLR4, toll-like receptor 4; MyD88, myeloid differentiation factor 88; p-NF- $\mathrm{B}$, phosphorylation-nuclear factor- $\kappa \mathrm{B}$; RPE, retinal pigment epithelial; COBRA, TLR4 inhibitor.

A

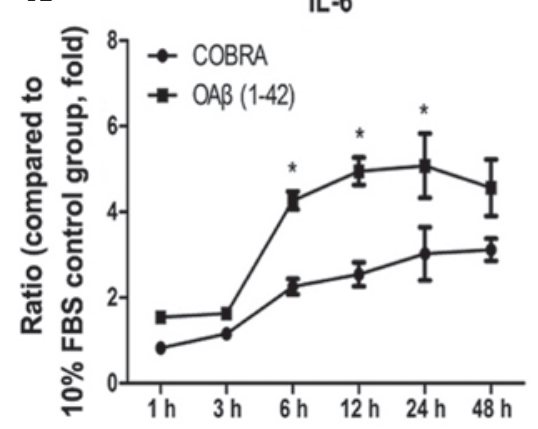

B

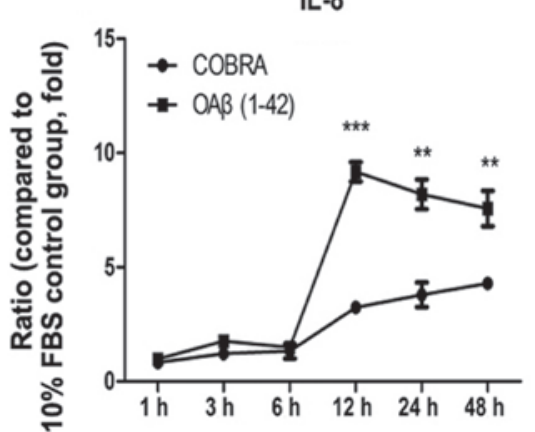

C

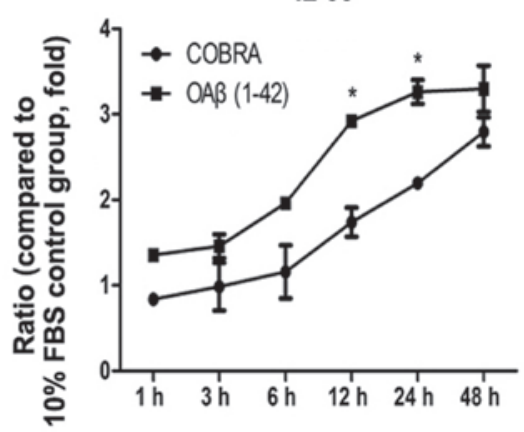

Figure 3. Effects of COBRA on the expression of the inflammatory cytokines (A) IL-6, (B) IL-8 and (C) IL-33 in retinal pigment epithelial cells exposed to OA $\beta 1-42$. Three independent experiments were performed and data are expressed as the mean \pm standard error. ${ }^{*} \mathrm{P}<0.05,{ }^{* *} \mathrm{P}<0.01$ and ${ }^{* * *} \mathrm{P}<0.01$ vs. COBRA group. FBS, fetal bovine serum; OA $\beta 1-42$, oligomeric form of A $\beta$; IL-6,-8,-33, interleukin- $6,-8,-33$; COBRA, TLR4 inhibitor.

Dunnett's test. For group comparisons, generalized linear mixed models were used as the present data was measured and obtained at various time-points. $\mathrm{P}<0.05$ was considered to indicate a statistically significant difference.

\section{Results}

Different A $\beta$ agents upregulate mRNA levels of cytokines in ARPE19 cells. In the current study, different $\mathrm{A} \beta$ agents were used to stimulate ARPE19 cells. The mRNA expression levels of all cytokines was shown in Fig. 1. In this assay, TLR4, MyD88 and NF- $\mathrm{BB}$ were upregulated at 3, 6 and $12 \mathrm{~h}$, respectively. Following a $24 \mathrm{~h}$ incubation, TLR4, MyD88 and $\mathrm{NF}-\kappa \mathrm{B}$ increased to $6.0 \pm 0.37,4.3 \pm 0.44$ and $5.4 \pm 0.32$-fold, respectively, in the OA $\beta 1-42$ group, which was significantly higher than in the other groups (Fig. 1A-C)

As presented in Fig. 1D-F, inflammatory factors were upregulated from 3 and $12 \mathrm{~h}$. IL-6, IL-8, IL-33 increased to $8.1 \pm 0.52,4.0 \pm 0.36$ and $3.7 \pm 0.19$-fold, respectively, in the
OA $\beta 1-42$ group respectively, which was significantly higher than other groups. The mRNA expression of angiogenic cytokines was upregulated from $6 \mathrm{~h}$. VEGF expression was increased to $19.3 \pm 3.28$ in the OA $\beta 1-42$ group, which was significantly higher compared with the other groups after $24 \mathrm{~h}$ (Fig. 1G). The mRNA expression level of bFGF increased by $3.0 \pm 0.30$-fold at $24 \mathrm{~h}$ in the OA $\beta 1-42$ group $(\mathrm{P}<0.01$; Fig. $1 \mathrm{H})$. Ang2 steadily increased from $6 \mathrm{~h}$ onwards (13.3 \pm 3.0 -fold; Fig. 1I). The expression of TLR2 and TLR3 mRNA was also determined; however, there was no significant difference compared with the control group (data not shown).

OA $\beta 1-42$ is involved in the activation of the TLR4 signaling pathway in ARPE19 cells. Western blot analysis detected the protein expression of TLR4, MyD88 and phosphorylation-NF- $\kappa$ B in ARPE19 cells treated with OA $\beta 1-42$ (Fig. 2). Fig. 2 indicates that the protein expression of TLR4 increased at $12 \mathrm{~h}$ and reached peak at $24 \mathrm{~h}$. The expression of TLR4 was upregulated 3.7-fold compared with 
A

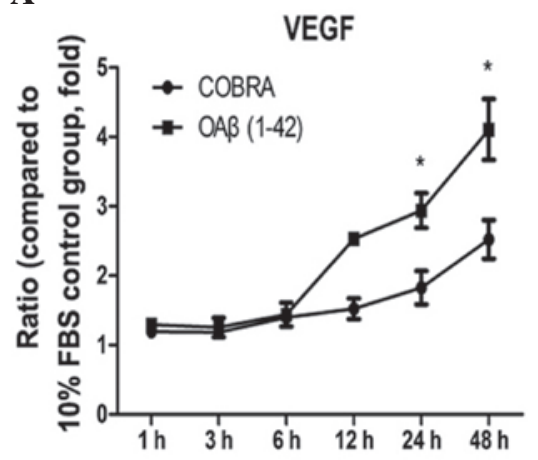

B

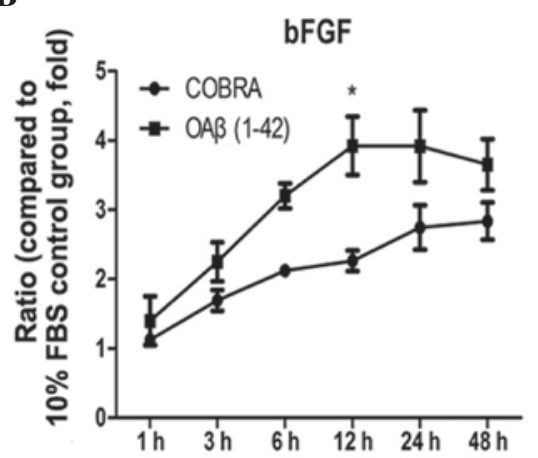

C

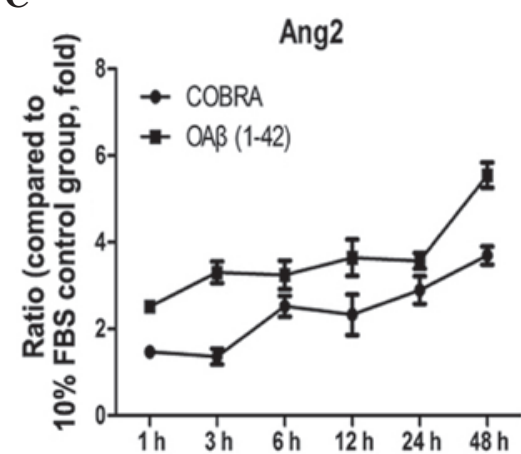

Figure 4. Effects of COBRA on the protein expression levels of angiogenic cytokines (A) VEGF, (B) bFGF and (C) Ang2 in OA $\beta 1-42$-treated retinal pigment epithelial cells. Three independent experiments were performed and data are expressed as the mean \pm standard error. ${ }^{*}<0.05$, vs. COBRA group. FSB, fetal bovine serum; OA $\beta 1-42$, oligomeric form of A $\beta$; COBRA, TLR4 inhibitor; VEGF, vascular endothelial growth factor; bFGF, basic fibroblast growth factor; Ang2, angiopoierin-2.

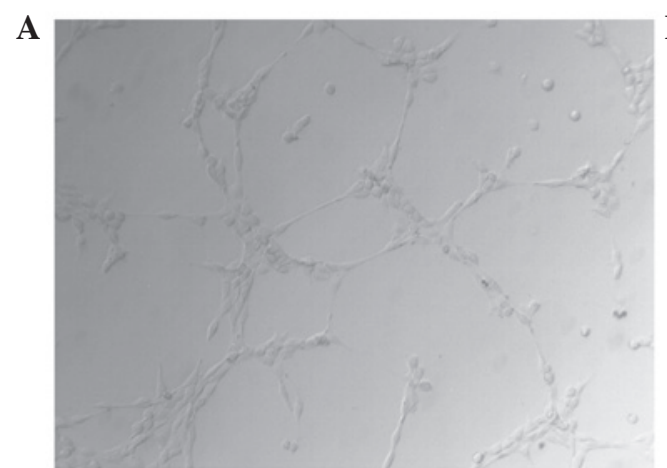

C

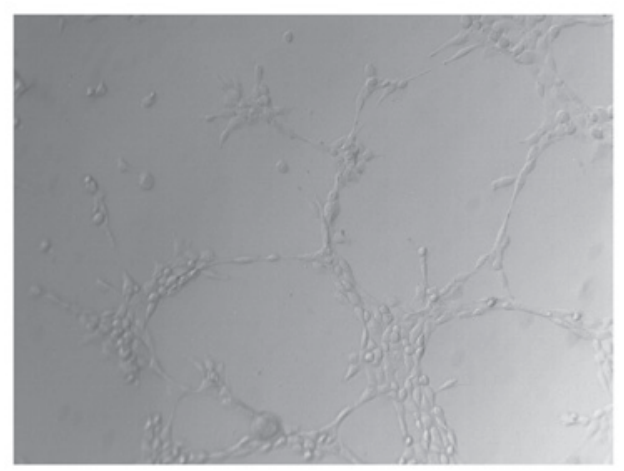

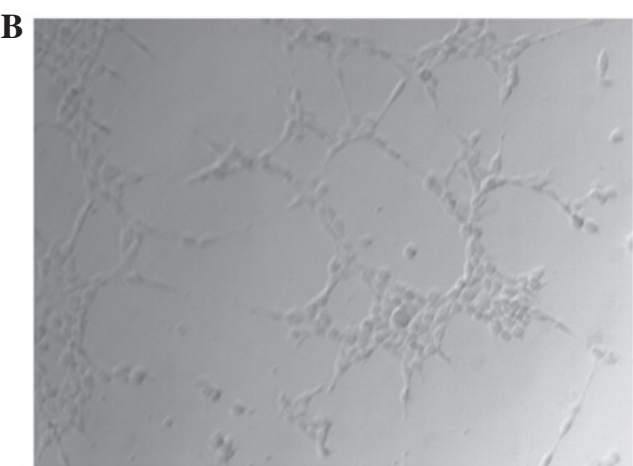

D

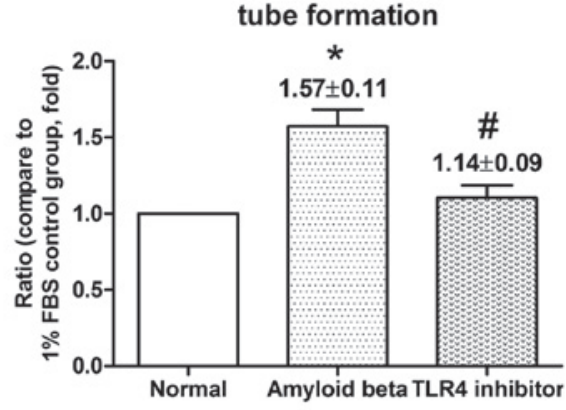

Figure 5. Effect of OA $\beta 1-42$ and COBRA on tube formation of human umbilical vein endothelial cells. The images of the angiogenic network in the (A) control group, (B) OA 1 1-42 group and (C) COBRA group. Magnification, x100. (D) Quantification of the length of the angiogenic network. Data were determined as network length and shown as the mean percentage control \pm standard error. ${ }^{*} \mathrm{P}<0.05$ vs. control; ${ }^{*} \mathrm{P}<0.05$ vs. OA 1 - 42 group. FBS, fetal bovine serum; TLR4, toll-like receptor 4; OA $\beta 1-42$, oligomeric form of A $\beta$; COBRA, TLR4 inhibitor.

the control group (Fig. 2A). Similarly, the expression levels of MyD88 and p-NF- $\kappa \mathrm{B}$ were also increased in RPE cells treated with OA $\beta 1-42(\mathrm{P}<0.01$ and $\mathrm{P}<0.001$ vs. $\mathrm{OA} \beta+$ COBRA; Fig. 2B and C).

Western blot analysis was also used to determine the effect of COBRA on the protein expression levels of MyD88 and p-NF- $\mathrm{kB}$. As presented in Fig. 2B and C the protein levels of MyD88 and NF- $\kappa B$ were significantly reduced in ARPE19 cells following COBRA treatment when compared with the OA $\beta 1-42$ group at 24 and $48 \mathrm{~h}$.

COBRA downregulates the expression of inflammatory and angiogenic factors in ARPE19 cells induced by OAß1-42. The protein expression level of inflammatory factors increased from $6 \mathrm{~h}$ of treatment in the two groups. IL- 8 was upregulated by $9.17 \pm 0.43$-fold at $12 \mathrm{~h}$ in the OA $\beta 1-42$ group $(\mathrm{P}<0.001$ vs. control). IL- 6 and IL-33 increased by $5.1 \pm 0.75$-fold and $3.3 \pm 0.14$-fold at $24 \mathrm{~h}$, respectively, in the OA $\beta 1-42$ group $(\mathrm{P}<0.05$ vs. control; Fig. $3 \mathrm{~A}$ and $\mathrm{C})$.

Furthermore, changes in the protein concentration of inflammatory and angiogenic factors in cells treated with COBRA and OA $\beta 1-42$ were detected (Figs. 3 and 4). IL-6 and IL-8 expression was significantly reduced at $12 \mathrm{~h}$ following COBRA treatment $(\mathrm{P}<0.05$ and $\mathrm{P}<0.001$ vs. the COBRA group, respectively). However, IL-33 expression in the COBRA group was at a similar level as the OA $\beta 1-42$ group at 
48 h (Fig. 3C). VEGF and Ang2 expression was increased by 4.1 \pm 0.44 -fold and 5.5 \pm 0.29 -fold at $4 \mathrm{~h}$, while bFGF, increased by $3.9 \pm 0.52$-fold at $24 \mathrm{~h}$ ( $\mathrm{P}<0.05$ vs. control; Fig. 4$)$. The levels of VEGF and bFGF were reduced in the COBRA group vs. the OA $\beta 1-42$ group $(\mathrm{P}<0.05$; Fig. $4 \mathrm{~A}$ and $\mathrm{B})$. No significant differences were identified between the OA $\beta 1-42$ group and the COBRA treatment group for Ang2 (Fig. 4C).

COBRA reduces capillary-like structure formation. The Matrigel tube formation assay is a quantifiable method of testing the angiogenic properties of compounds on vascular endothelial cells in vitro, as it determines the ability of endothelial cells to form capillary-like structures. Cells were cultured on Matrigel-coated wells for $8 \mathrm{~h}$. HUVECs cultured in the cell supernatant of RPE cells, which were exposed to COBRA, exhibited an impaired capacity to form a regular network (due to impaired tube formation ability; Fig. 5C and D). The length of the angiogenic network indicated a significant difference between the COBRA and OA $\beta 1-42$ treatment groups (Fig. 5D).

\section{Discussion}

Accumulation of drusen in the extracellular compartment between the choroid and the RPE is an early event in the course of AMD $(3,4)$. A $\beta$ is an important constituent of drusen and has been associated with the pathogenesis of AMD $(3,4)$, which has been verified by AMD mice models (25) and RPE cells (7). A previous study also indicated that $A \beta$ may induce inflammation and barrier disruption in RPE cells in vivo (11). Additionally, it has been demonstrated that chronic inflammation has a prominent role in the pathogenesis of AMD (26). However, the underlying molecular mechanism is largely unknown. To investigate the dysfunction of $A \beta$-stimulated RPE cells, the current in vitro study was conducted, focusing on angiogenic and inflammatory factors. The present study also demonstrated that OA $\beta 1-42$ activates the TLR4, MyD88 and NF- $\mathrm{NB}$ signaling pathways, and induced the expression of inflammatory and angiogenic factors in ARPE19 cells. The secretion of cytokines triggered by exposure to OA $\beta 1-42$-was significantly reduced when COBRA was applied as a treatment. The capillary-like structures that form as a response to OA $\beta 1-42$ were also reduced following COBRA treatment.

The current study verified that OA $\beta 1-42$ was the pathological form of $A \beta$ and was responsible for the changes in the mRNA expression levels of cytokines rather than the other forms of $A \beta$. Additionally, mRNA levels were upregulated, particularly in the OA $\beta 1-42$ treatment groups (Fig. 1). The present study also determined mRNA expression levels of other TLRs; however, TLR2 and TLR3 were not increased following OA $\beta 1-42$ stimulation (data not shown). Therefore, TLR4 was selected as a target to investigate the pathological function of OA $\beta 1-42$ on RPE cells.

Numerous studies have demonstrated the diverse response to TLR4 activation including, the intracellular expression of adaptor protein MyD88, the phosphorylation of $\mathrm{I} \kappa \mathrm{B} \alpha$ and $\mathrm{NF}-\kappa \mathrm{B}$, and elevated mRNA expression of TNF- $\alpha$, IL-6 and IL-8, along with monocyte chemoattractant protein-1 (MCP-1) (27-29). Qi et al (27) indicated that retinal ischemia-reperfusion injury may trigger the TLR4 signaling pathway through MyD88, TNF receptor-associated factor 6
(TRAF6) and NF- $\kappa B$, leading to the release of mature IL-1 $\beta$ and IL-18. Smith et al (28) revealed that infection of macrophages enhanced TNF- $\alpha$, IL-6 and IL- 8 gene expression and protein production in response to the TLR4 ligand (lipopolysaccharide) stimulation. These findings suggest that TLR4-signaling activation, triggered by damage- and pathogen-associated molecular patterns, regulated the release of inflammatory factors in response to various injuries. The current results were consistent with previous studies, and found that OA $\beta 1-42$ triggered TLR4 signaling pathway through MyD88 and NF- $\kappa$ B in ARPE19 cells. Additionally, COBRA was able to attenuate the expression of MyD88 and $\mathrm{p}-\mathrm{NF}-\kappa \mathrm{B}$ in OA $\beta 1-42$-treated RPE cells. These results suggest the potential function of the TLR4 signaling pathway in the pathological mechanisms of AMD.

The present study indicates that mRNA and protein levels of VEGF, bFGF and Ang2 were upregulated, in the OA $\beta 1$-42-treated groups. VEGFA (also termed VEGF165) is considered to be a major angiogenic factor to date (30). bFGF is also important in vascular generation and fibrosis of endothelial cells, RPE cells and membrane formation $(31,32)$. Angiopoietin-2 is also a member of the angiogenic factor family, it facilitates VEGF-induced neovascularization and initiates neovascularization (33). The current results are consistent with those of Yoshida et al (7), as stimulation of human RPE cells with $A \beta$ resulted in the altered expression of angiogenic genes, specifically VEGF. The current study provides further evidence that $A \beta$ accumulation affects the balance of angiogenic factors in RPE cells, which may be a key contributor to the development of 'wet' AMD (7).

Cytokines are key drivers of inflammation and their imbalances are often implicated in diseases. Cytokines have gained attention due to their importance in AMD pathophysiology (34). Additionally, IL-6, IL-8 and IL-33 were upregulated in the cell group treated with OA $\beta 1-42$. IL-6 is a powerful cytokine that mediates the inflammatory response in a variety of disease states and is implicated in the progression of AMD (34). A previous clinical study determined that the aqueous humor from patients with AMD contains higher concentrations of IL-6 and IL-8 (35). IL-8 is a notable cytokine as its expression may be promoted by IL-1 $\beta$ via direct and indirect mechanisms in RPE cells. Gene microarrays indicated that the mRNA levels of IL-1 $\beta$ and IL-8 were significantly expressed, which is consistent with the present findings (36). In the current study, the concentration of IL- 8 increased by 9.17-fold in OA $\beta 1$-42-treated RPE cells when compared with the control group. Therefore, IL-8 may account for the observed accumulation of inflammatory cells in the regions of drusen formation in patients with AMD. IL-33 is also important in human inflammatory diseases, and its high level of expression was detected in the inflammatory status of various tissues (37). However, in the present study, IL-33 increased slightly in the COBRA treatment group and it almost recovered to a similar level as the OA $\beta 1-42$ only group following $48 \mathrm{~h}$. These results provide support for the hypothesis that OA $\beta 1-42$ triggers inflammatory responses in RPE cells and the production of inflammatory factors aiding in the development of AMD. However, inflammatory factors are only one aspect of the progression of AMD.

The present study concluded that COBRA regulates the expression of IL-6, IL-8, IL-33, VEGF, bFGF and Ang2 
through suppressing MyD88 and p-NF- $\kappa \mathrm{B}$ activation. However, with prolonged exposure, the levels of IL-6, IL-8, IL-33, VEGF and bFGF in the COBRA treatment group approached a similar level as the OA $\beta 1-42$ group. Therefore, the release of cytokines in RPE cells induced by $A \beta$ is a complex mechanism, which involves numerous signaling pathways. Previous studies demonstrated that $\mathrm{A} \beta$-induced RPE barrier disruption and expression of inflammation factors was associated with NF- $\kappa \mathrm{B}, \mathrm{ERK} 1 / 2$ and p38 MAPK signaling $(14,15)$. The TLR4 signaling pathway is a possible mechanism that is involved with stimulation of inflammatory and angiogenic factors in RPE cells induced by $A \beta$. This supports the hypothesis that $\mathrm{A} \beta$ promotes local inflammation and angiogenic factors near drusen sites and within the surrounding RPE layer that may facilitate the pathogenesis of AMD.

\section{Acknowledgements}

The present study was supported by the Beijing Nova Program (grant no. Z131102000413004).

\section{References}

1. Coleman HR, Chan CC, Ferris FL III and Chew EY: Age-related macular degeneration. Lancet 372: 1835-1845, 2008.

2. Jager RD, Mieler WF and Miller JW: Age-related macular degeneration. N Engl J Med 358: 2606-2617, 2008.

3. Bird AC, Bressler NM, Bressler SB, Chisholm IH, Coscas G, Davis MD, de Jong PT, Klaver CC, Klein BE, Klein R, et al; The International ARM Epidemiological Study Group: An international classification and grading system for age-related maculopathy and age-related macular degeneration. Surv Ophthalmol 39: 367-374, 1995.

4. Bressler NM, Silva JC, Bressler SB, Fine SL and Green WR: Clinicopathologic correlation of drusen and retinal pigment epithelial abnormalities in age-related macular degeneration. Retina 14: 130-142, 1994.

5. Ferreira ST, Vieira MN and De Felice FG: Soluble protein oligomers as emerging toxins in Alzheimer's and other amyloid diseases. IUBMB Life 59: 332-345, 2007.

6. Johnson LV, Leitner WP, Rivest AJ, Staples MK, Radeke MJ and Anderson DH: The Alzheimer's A beta-peptide is deposited at sites of complement activation in pathologic deposits associated with aging and age-related macular degeneration. Proc Natl Acad Sci USA 99: 11830-11835, 2002.

7. Yoshida T, Ohno-Matsui K, Ichinose S, Sato T, Iwata N, Saido TC, Hisatomi T, Mochizuki M and Morita I: The potential role of amyloid beta in the pathogenesis of age-related macular degeneration. J Clin Invest 115: 2793-2800, 2005.

8. Teplow DB, Lazo ND, Bitan G, Bernstein S, Wyttenbach T, Bowers MT, Baumketner A, Shea JE, Urbanc B, Cruz L, et al: Elucidating amyloid beta-protein folding and assembly: A multidisciplinary approach. Acc Chem Res 39: 635-645, 2006.

9. Hoyer W, Grönwall C, Jonsson A, Ståhl S and Härd T: Stabilization of a beta-hairpin in monomeric Alzheimer's amyloid-beta peptide inhibits amyloid formation. Proc Natl Acad Sci USA 105: 5099-5104, 2008.

10. Gouras GK, Olsson TT and Hansson O: $\beta$-Amyloid peptides and amyloid plaques in Alzheimer's disease. Neurotherapeutics 12: 3-11, 2015.

11. Liu RT, Gao J, Cao S, Sandhu N, Cui JZ, Chou CL, Fang E and Matsubara JA: Inflammatory mediators induced by amyloid-beta in the retina and RPE in vivo: Implications for inflammasome activation in age-related macular degeneration. Invest Ophthalmol Vis Sci 54: 2225-2237, 2013.

12. Bruban J, Glotin AL, Dinet V, Chalour N, Sennlaub F, Jonet L, An N, Faussat AM and Mascarelli F: Amyloid-beta(1-42) alters structure and function of retinal pigmented epithelial cells. Aging Cell 8: 162-177, 2009.
13. Liu RT, Wang A, To E, Gao J, Cao S, Cui JZ and Matsubara JA: Vinpocetine inhibits amyloid-beta induced activation of NF- $\kappa \mathrm{B}, \mathrm{NLRP} 3$ inflammasome and cytokine production in retinal pigment epithelial cells. Exp Eye Res 127: 49-58, 2014.

14. Cao L, Liu C, Wang F and Wang H: SIRT1 negatively regulates amyloid-beta-induced inflammation via the NF- $\kappa \mathrm{B}$ pathway. Braz J Med Biol Res 46: 659-669, 2013.

15. Liu XC, Liu XF, Jian CX, Li CJ and He SZ: IL-33 is induced by amyloid- $\beta$ stimulation and regulates inflammatory cytokine production in retinal pigment epithelium cells. Inflammation 35: 776-784, 2012.

16. Jantaratnotai N, Ling A, Cheng J, Schwab C, McGeer PL and McLarnon JG: Upregulation and expression patterns of the angiogenic transcription factor ets-1 in Alzheimer's disease brain. J Alzheimers Dis 37: 367-377, 2013.

17. Fioravanzo L, Venturini M, Di Liddo R, Marchi F, Grandi C, Parnigotto PP and Folin M: Involvement of rat hippocampal astrocytes in $\beta$-amyloid-induced angiogenesis and neuroinflammation. Curr Alzheimer Res 7: 591-601, 2010.

18. Kijlstra A, La Heij E and Hendrikse F: Immunological factors in the pathogenesis and treatment of age-related macular degeneration. Ocul Immunol Inflamm 13: 3-11, 2005.

19. Bryant CE, Spring DR, Gangloff M and Gay NJ: The molecular basis of the host response to lipopolysaccharide. Nat Rev Microbiol 8: 8-14, 2010.

20. Seddon JM, Santangelo SL, Book K, Chong S and Cote J: A genomewide scan for age-related macular degeneration provides evidence for linkage to several chromosomal regions. Am J Hum Genet 73: 780-790, 2003.

21. Abecasis GR, Yashar BM, Zhao Y, Ghiasvand NM, Zareparsi S, Branham KE, Reddick AC, Trager EH, Yoshida S, Bahling J, et al: Age-related macular degeneration: A high-resolution genome scan for susceptibility loci in a population enriched for late-stage disease. Am J Hum Genet 74: 482-494, 2004.

22. Kindzelskii AL, Elner VM, Elner SG, Yang D, Hughes BA and Petty HR: Toll-like receptor 4 (TLR4) of retinal pigment epithelial cells participates in transmembrane signaling in response to photoreceptor outer segments. J Gen Physiol 124: $139-149,2004$

23. Zhou X, Yuan L, Zhao X, Hou C, Ma W, Yu H and Xiao R: Genistein antagonizes inflammatory damage induced by $\beta$-amyloid peptide in microglia through TLR4 and NF- $\kappa \mathrm{B}$. Nutrition 30: 90-95, 2014.

24. Mohr T and Desser L: Plant proteolytic enzyme papain abrogates angiogenic activation of human umbilical vein endothelial cells (HUVEC) in vitro. BMC Complement Altern Med 13: 231, 2013.

25. Malek G, Johnson LV, Mace BE, Saloupis P, Schmechel DE, Rickman DW, Toth CA, Sullivan PM and Bowes Rickman C: Apolipoprotein E allele-dependent pathogenesis: A model for age-related retinal degeneration. Proc Natl Acad Sci USA 102: 11900-11905, 2005

26. Buschini E, Piras A, Nuzzi R and Vercelli A: Age related macular degeneration and drusen: Neuroinflammation in the retina. Prog Neurobiol 95: 14-25, 2011.

27. Qi Y, Zhao M, Bai Y, Huang L, Yu W, Bian Z, Zhao M and Li X: Retinal ischemia/reperfusion injury is mediated by Toll-like receptor 4 activation of NLRP3 inflammasomes. Invest Ophthalmol Vis Sci 55: 5466-5475, 2014.

28. Smith PD, Shimamura M, Musgrove LC, Dennis EA, Bimczok D, Novak L, Ballestas M, Fenton A, Dandekar S, Britt WJ and Smythies LE: Cytomegalovirus enhances macrophage TLR expression and MyD88-mediated signal transduction to potentiate inducible inflammatory responses. J Immunol 193: 5604-5612, 2014.

29. Park MY and Mun ST: Carnosic acid inhibits TLR4-MyD88 signaling pathway in LPS-stimulated 3T3-L1 adipocytes. Nutr Res Pract 8: 516-520, 2014.

30. Novack GD: Pharmacotherapy for the treatment of choroidal neovascularization due to age-related macular degeneration. Annu Rev Pharmacol Toxicol 48: 61-78, 2008.

31. Stahl A, Paschek L, Martin G, Feltgen N, Hansen LL and Agostini HT: Combinatory inhibition of VEGF and FGF2 is superior to solitary VEGF inhibition in an in vitro model of RPE-induced angiogenesis. Graefes Arch Clin Exp Ophthalmol 247: 767-773, 2009.

32. Nagineni CN, Samuel W, Nagineni S, Pardhasaradhi K, Wiggert B, Detrick B and Hooks JJ: Transforming growth factor-beta induces expression of vascular endothelial growth factor in human retinal pigment epithelial cells: Involvement of mitogen-activated protein kinases. J Cell Physiol 197: 453-462, 2003. 
33. Asahara T, Chen D, Takahashi T, Fujikawa K, Kearney M, Magner M, Yancopoulos GD and Isner JM: Tie2 receptor ligands, angiopoietin-1 and angiopoietin-2, modulate VEGF-induced postnatal neovascularization. Circ Res 83: 233-240, 1998.

34. Seddon JM, George S, Rosner B and Rifai N: Progression of age-related macular degeneration: Prospective assessment of C-reactive protein, interleukin 6, and other cardiovascular biomarkers. Arch Ophthalmol 123: 774-782, 2005.

35. Jonas JB, Tao Y, Neumaier M and Findeisen P: Cytokine concentration in aqueous humour of eyes with exudative age-related macular degeneration. Acta Ophthalmol 90: e381-e388, 2012.
36. Kurji KH, Cui JZ, Lin T, Harriman D, Prasad SS, Kojic L and Matsubara JA: Microarray analysis identifies changes in inflammatory gene expression in response to amyloid-beta stimulation of cultured human retinal pigment epithelial cells. Invest Ophthalmol Vis Sci 51: 1151-1163, 2010.

37. Préfontaine D, Nadigel J, Chouiali F, Audusseau S, Semlali A, Chakir J, Martin JG and Hamid Q: Increased IL-33 expression by epithelial cells in bronchial asthma. J Allergy Clin Immunol 125: $752-754,2010$. 